\title{
The association of slimming with eating disorders
}

\author{
B Y ANN LEADER \\ St Gabriel's Hospital, Cabintealy, Dublin, Republic of Ireland
}

Chronic obesity is a very difficult condition to treat and the statistics are appalling. Of patients who lose weight on any particular diet or exercise programme $90 \%$ put it all back on again within a 2 -year period.

Losing weight in the short term is a fairly easy and straightforward business. Nearly everyone can stick to a low-energy diet and step up their exercise for 1 week. Indeed, I have never met a patient who has failed to lose weight for short periods.

Achieving safe permanent weight loss is a different kettle of fish and requires infinite patience, total commitment and strategic planning.

I will now describe the plight of the perpetual dieter whose life revolves around food, who is always on a diet, but who never succeeds in losing weight. There are three distinct phases of dieting that are characteristic of this unfortunate person.

\section{PHASE ONE:}

\section{'Hope springs eternal in the human breast'}

In this phase the dieter starts afresh. The old slate of failure is wiped clean and the new miracle method is taken on board with vigour and optimism.

The person usually chooses some day symbolic of a new beginning, New Year's Day, the first day of Lent, Mondays, or in the case of many disillusioned dieters, every single morning. People rarely start their diets on rainy Sunday afternoons; it smacks of failure before it even begins.

The diet chosen is often new, adventurous and difficult, demanding total concentration and dedication. Alternatively, it may be the 'old reliable' which has proved over the years to produce the most rapid weight loss in the least possible time.

The diet is strictly adhered to and becomes the main focus of attention. Calorie counting is obsessive and meal times are set aside with rigidity and reverence.

The dieter meets with great success for the first $5 \mathrm{~d}$. This is particularly true of the low-carbohydrate diets where water is lost more quickly. The rapid weight loss is accompanied by feelings of power and euphoria.

Often, the dieter, spurred on by success, eats even less than permitted. She believes that this demonstrates even greater willpower and self control. This wonderful state of affairs lasts on average between 5 and $10 \mathrm{~d}$.

At the end of the first week hunger and boredom are setting in. It becomes difficult to get the expensive and exotic ingredients. The 5-mile walk that was light and joyful on Monday has become a tedious bore by Sunday.

As self-pity and misery increase, the old familiar cravings become harder to ignore. The dieter knowingly waits for, even welcomes, any excuse to pull the trigger that will blow this latest and greatest diet to bits.

The die is cast and before reason prevails, the first bar of chocolate is already winding its way down the gullet. Once the gravity of the situation is fully grasped it is already too late and the battle of the bulge is once again postponed. 


\section{PHASE TWO:}

'Eat, drink and be merry, for tomorrow we diet'

The moment the dieter feels she has 'broken out' she enters phase two. Although the initial damage in terms of energy may not be very great, it is the psychological reaction to the break-out that determines subsequent events.

Her thoughts run on the following lines: 'I am a hopeless case. I have no willpower whatsoever. I give in at the slightest provocation. Now that I have blown it I may as well go the whole hog and eat away to my heart's content'.

'Tomorrow I will try again and give up for ever cakes, sweets and biscuits. This is my last chance to savour them without restriction.' Now that permission has been granted she can eat all she wants with relish and enjoyment.

By the time tomorrow comes she is so disgusted with herself that she has no heart or stomach for starvation. She stands on the scales only to discover that what she lost in a week of hell has been almost completely regained after a few hours of feasting.

If dieting is this difficult, she concludes, she would rather be fat and happy. She is now poised to enter the next phase.

\section{PHASE THREE:}

'I am now stepped in so far that should I wade no more returning were as tedious as go o'er'

This is the phase where the dieter makes no attempt to diet. She is angry and disillusioned with the whole business. Whereas before she would automatically zone in on any discussion of food or calories, she now assiduously avoids them.

She stops weighing, takes no exercise, gives up the gym and sleeps in on Sundays. She eats what she likes, when she likes. In severe cases she stops going out as she cannot bear to be seen 'fat and ugly' and so obviously out of control.

Food becomes her only comfort and she turns to it like an old friend. She is full of shame and often eats in secret.

Sooner or later she is confronted by well-meaning family and friends. This usually results in a row and gives her an excuse to eat even more. Her weight breaks all past records and soars to new heights.

In desperation she sees the light and is ready for redemption once more. She rounds up all the old heavy-weights and together they sniff around for new solutions. The grapevine is extremely active and is always eager to yield up new and painless remedies.

Eureka! Luck at last! She finds the new drug, the diet of diets, the foolproof method. She enters phase one again and history repeats itself over and over and over again.

Most people are overweight because of a genetic tendency to put on weight easily. In order to lose weight successfully, they are condemned to eat less than the average person or exercise more for the rest of their lives. This is no easy task. It involves long-term energy restriction, a regular exercise programme and lots of support. Let us first consider the ideal diet.

\section{DIET}

The golden rule of dieting is to make rules that can be kept. This means that the diet must be practical, flexible and able to withstand weddings, weekends and holidays. I 
would recommend a daily energy intake of between $4 \cdot 2$ and 5.0 MJ (1000-1200 kcal) with at least two planned 'break-outs' per week. One planned treat should be at a designated time and the other should act as a 'floating' break. If the dieter is caught on the hop by an impulsive break-out, she can then convert it into her preplanned treat. This limits the amount of food eaten, removes guilt and prevents 'blow-out' binges. The dieter can still perceive herself as a good dieter because she is sticking to her own rules. If possible, the designated break-out should coincide with the trigger times of maximum temptation. These occur most commonly in the evenings, at weekends and during times of stress and change.

Many women report that they are more vulnerable to carbohydrate cravings in the premenstrual week and it may be an idea to relax the diet for 1 week in 4 weeks as a preventive measure at this time. The 'break-out' food should include all the forbidden goodies like chocolates, biscuits and other dangerous delectables. There should, however, be a preplanned upper limit and this should err on the side of generosity. The whole idea is to teach the dieter that all foods can be eaten and enjoyed on a regular basis.

No food is absolutely forbidden and, therefore, the sense of deprivation is lessened. When the treat is over, the dieter knows that within days she can experience the glorious sensations once more.

The daily diet should be delicious. It has to lack calories and must, therefore, be enhanced by taste and variety. The palate should be pampered with the finest and freshest of fare. The dieter's plate must take priority. Those family members with energy intake to spare can take care of yesterday's bake and suffer the burnt offerings. Food that is not enjoyable should never be eaten. I remember a failed dieter telling me she would buy a big bag of Cadbury's every evening and then, as some kind of atonement, add in a low-fat yoghurt and cottage cheese! This was, of course, only adding to her energy problem.

The dieter must train herself to indulge in extravagant non-fattening foods. She should splurge out on unusual fish and fowl. Cheap chicken and cod should give way more often to the less cautious pheasant and the low-calorie grouse. Most dieters are notoriously stingy when it comes to spending money on the diet. They shy away from grapes or kiwi fruits, preferring the safe, thrifty substitutes, apples and bananas. The great paradox is that when they decide to break the diet, they can shell out quite unconcernedly for the most lavish and fattening of foods.

Meals should be eaten three or four times daily at times of maximum peace and quiet. Breakfast in bed, if possible. Take up the tray with the pre-ordained breakfast, the red rose and the Irish Times. The evening meal should be an exquisite, enjoyable experience. How often this is not the case! The more usual scenario features a tired, tense housewife trying to get the whole sordid affair over as quickly as possible. Her hungry, hassled husband needs an instant food fix. He cannot be deprived of history in the making and so requires peace and solitude when he tunes in compulsively to the 6 o'clock news. The starving hordes of cranky children need to be stuffed with food to ensure their silence and his comfort. The cook is getting more frazzled by the minute and gulps down any old makeshift meal that comes her way. She contents herself with scraps. After $1 \mathrm{~h}$, the kitchen glistens, the cherubs sleep and her happy husband, hushed with food, is whistling softly in the shower. The dissatisfied dieter is already dreaming of 'Toblerone'. This sad state of affairs could be reversed with a little forward planning. The children could be fed 
their favourite dinner at 5 o'clock, long before breaking point is reached. Husband could watch his 6 o'clock news free from the hustle and bustle of meal time. The cook could treat herself to a relaxing predinner soak in Radox, happy in the knowledge that her modern partner is bonding with and bedding down their cherished offspring. Why should he be deprived of the precious moments!

The happy couple could eat at 8 o'clock, alone and uninterrupted. A microwave helps to complete the miracle!

Despite the most exotic ingredients and the most inventive cooking, a diet is still a diet. Pleasures that greyhound types take for granted are denied the potential fatty. This pleasure must be replaced by regular non-food treats. These treats should be slightly sensuous and self-indulgent. Most dieters are disgusted with their bodies and find it hard to luxuriate themselves in ways other than eating. They should try. A Friday facial is just as nice as fish and chips. Fresh freesias come a close second to sticky buns in Bewleys and a quiet hour alone in the garden is both cheap and therapeutic. If the dieter can train herself to grasp every potential pleasure in her life and to do so without the spoiling spectre of guilt, she will be well able to cope with the inevitable drudgery of dieting.

\section{EXERCISE}

Exercise is even more important than dieting. When a person reduces her energy intake, the body responds by reducing its energy requirements. When the dieter goes back to her usual eating, the weight piles on. This is why dieting makes you fat, particularly if the energy restriction is extreme. The only safe way this effect can be neutralized is by increasing exercise. As a general rule, if weight is not shifting with diet alone, do not decrease energy further; increase exercise instead. Exercise speeds up the body's metabolism and produces a feeling of well-being and relaxation.

Provided one is healthy, the only rule about exercise is that it is enjoyable. Fat people often hate exercise and have no confidence in their sporting ability. They remember the ridicule they endured as children when they first had to compulsorily expose their folds on the playing field. They often gave up completely because of the humiliation. It is important to woo them back and give them a positive experience of exercise. One trick is to combine their exercise with a pleasurable activity. Instead of walking to the watch, which can indeed be a dull affair, they should walk to their favourite radio programme. The time slips by and they quickly confuse the two pleasures. They should enhance motivation by joining a gym. If there are particular exercise regimens for fat people, so much the better.

If the exercise is varied and sociable, it will really become a pleasure. As the overweight person gets fitter and leaner, their enjoyment increases and they discover sporting skills that were dormant for years through lack of confidence. They must keep moving, keep going and keep at it. I cannot stress the importance of regular exercise in any weight reduction programme. If many overweight patients ate the same and really increased their exercise, most of them would start losing weight instead of gaining.

\section{SUPPORT}

The dieter should have full insight into the inevitable frustrations associated with long-term dieting. She should enlist as much support as possible. She should vow that she 
will never miss support sessions. It is not possible to never wander off the diet. It may not be realistic to maintain daily exercise, but it is within everybody's ability to make a commitment that they will be faithful to their group, come hell or high water. Most dieters give up everything when the diet breaks down. This is precisely the time when they need to face the music, to confront the crisis and to be sent home full of renewed determination.

There are several support groups available: Weight Watchers, Unislim, Overeaters Anonymous, etc. The dieter should choose the group that works best for her. No group will work if it is abandoned at the first failure.

A minority of overweight patients need to be fat for complex psychological reasons. These patients need more specialized help. They need individual assessment and may benefit greatly from individual therapy or group therapy designed to deal with their particular problems.

When a patient with weight to lose gets into the rhythm of a good diet and healthy exercise, it can be a very positive and pleasant way of life. At first, the pounds slip off slowly and quietly. Gradually the pounds turn into stones. Exercise shapes and tones at gentle speed and the bedraggled body slowly blossoms into a thing of beauty and a joy for ever. 